\title{
Determination of Building Penetration Loss of Gsm Signals, Using Selected Buildings in Orhuwhorun, Delta State, Nigeria as a Case Study
}

\author{
${ }^{1}$ Idim, A. I and ${ }^{2}$ Anyasi F.I \\ ${ }^{I}$ Department of Electrical and Electronic Engineering, Petroleum Training Institute, P.M.B 20, Effurun, Delta \\ State, Nigeria. \\ ${ }^{2}$ Department Electrical and Electronic Engineering, Ambrose Alli University, P.M.B 14, Ekpoma. Edo State, \\ Nigeria.
}

\begin{abstract}
Outages of GSM signals may be experienced at some indoor locations even where there are strong outdoor receptions. This is often traced to the building penetration loss, which accounts for increased attenuation of received GSM signal level when a mobile signal device is moved indoor from outdoor. The signal degradation increases with increasing penetration loss. Penetration loss depends on the building material type, amongst others and adds to the overall path loss of a link. In this work, measurements of two existing GSM Operators' signals level were made outside and inside two selected buildings-concrete and block, which represent the prevalent building types in Orhuwhorun, Delta State, Nigeria. A Samsung Galaxy GT-35000 mobile phone with RF signal tracker software installed in it was used and the results shows an average loss of $10.62 \mathrm{dBm}$, and $4.25 \mathrm{dBm}$ for the concrete and block buildings, respectively. This results will help service network providers in future site-specific planning.
\end{abstract}

\section{Introduction}

The return of democratization in Nigerian political system in May 1999 brought about many changes in the polity and economy. Of significant importance is the introduction of global mobile communication system popularly called GSM (GSM-1800) which operates in the $1800 \mathrm{MHz}$ frequency band. GSM-1800 provides much higher capacity in terms of number of users than GSM-900 which operates in the $900 \mathrm{MHz}$ range [Antalainen, 2003]. As at today the GSM providers in the country include MTN Nigeria Limited and Airtel Nigeria, Limited Globacom Nigeria Limited and and Etisalat. With the advent of GSM in Nigeria telecommunication services have been brought nearer to an average individual in the country [Adewoye, 2010]. However GSM is not without problems as it is not an uncommon sight to see a mobile user at some location move from inside to outside a building in order to have an uninterrupted communication. This is because when a GSM signal passes through a medium not transparent to electromagnetic wave it experiences a loss known as penetration loss. The most important is building penetration loss, as this affects the signal strength received inside a building due to an external transmitter (outdoor-to-indoor reception). Penetration loss contributes to the overall loss of a communication link [Rappaport, 2003]. The objective of this work was therefore to determine the penetration loss of concrete and block buildings, two building materials prevalent in Orhuwhorun, Delta State to see to what extent GSM signal strength are affected by these materials. The findings will enable GSM service providers in site-specific planning.

Most mobile radio systems operate in areas where there is no direct line-of-sight path between the transmitter and the receiver antennas. Due to multiple reflections from various objects the electromagnetic waves travel along different paths of varying lengths to the receiver simultaneously. The interaction between these waves therefore causes multipath fading, resulting in increased path loss as the distance between the transmitter and receiver increases [Rappaport, 2003].

Building penetration loss accounts for the increase in attenuation of the received signal observed when the mobile is moved from outside to inside a building. RF signal strength received inside a building due to an external transmitter are affected by various factors,

Frequency of Transmission:- This is one of the most significant factors which influence penetration loss. Results of researchers, [Rice, 1959] point to the fact that Penetration losses decrease slightly with increase in transmission frequency.

Height:- This is the height where the receiver, positioned inside a building, receives from an external transmitter. Generally penetration loss is known to decrease with height, because the interference caused by adjacent structures diminishes with increasing height and the signal strength becomes greater due to the fact that LOS path is likely to exist above the urban clutter [Tanis and Pilato, 1993][ Turkmani and Toledo, 1991][ Walker, 1983]. 
Building Structure and Internal Layout:- Propagation into (and inside) buildings are reported have a more complex multipath structure than that of the terrestrial mobile radio channel. Propagation of RF waves inside buildings are characterized by rapid fluctuations over very short travel distances (a few wavelengths) or short time duration (on the order of seconds) as illustrated in Fig.1. This is mainly due to the building structure, layout of rooms, type of construction materials and the furniture. Thus the signal loss inside a factory building is quite different from the loss inside an office building due to the differences in the structure and the materials used [Rappaport, 2003] [ Turkmani and Toledo, 1991][ Walker, 1983].

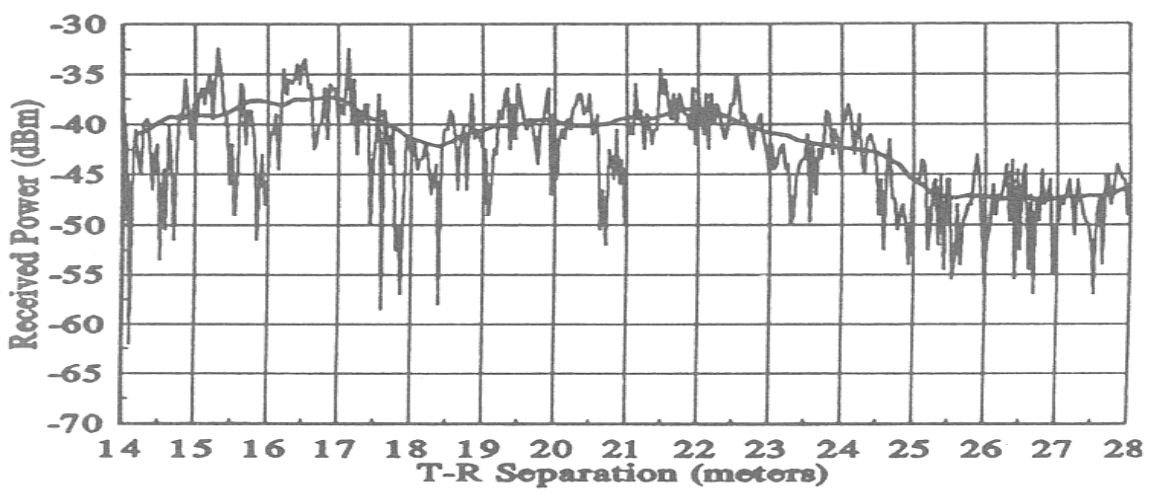

Fig.1 Typical plot of indoors Received RF Power versus range in meters [Rappaport, 2003]

Physical Surroundings/ Conditions :- Physical surroundings around and within any building also affect the signal strength within since RF waves may enter the building directly from the transmitting antenna (line-ofsight) or may be bounced off the many reflecting surfaces presented by the surrounding buildings. Once inside the building, the field encounters a wide array of objects which shields or reflects the RF signal or cause losses to it. Penetration losses are generally higher in urban environments [Rappaport, 2003][Attah, 2013].

Other Factors:- Other factors include the position of the transmitter, dimension of window area, direction of incident wave arrival and the absorption of moisture (water) by building materials. It is generally reported that under water absorption the relative permittivity of building materials increase, resulting in increased losses compared with the dry case [Horikoshi, Tanaka and Morinaga, 1986] [Hasted and Shah, 1964]

\section{Calculation of Penetration Loss}

For a given building the average building penetration loss may be computed using equation (1) [Caluyo and Dela Cruz, 2011]

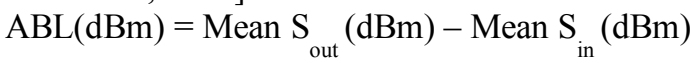

Where ABL is the Average Penetration Loss in $\mathrm{dBm}$, Mean $\mathrm{S}_{\text {out }}$ is Mean signal level outside the building in $\mathrm{dBm}$ and Mean $\mathrm{S}_{\mathrm{in}}=$ Mean signal level inside the building in $\mathrm{dBm}$

\section{Materials And Methods}

A case study method was used on two different buildings, a concrete and the other, block. A Samsung Galaxy phone, with RF Signal Tracker software installed in it, was used for this purpose and the results obtained were compared

\section{Description of Measurement Sites}

The measurement sites were concrete slab and block bungalow residential buildings in Orhuwhorun, a sub-urban area in Udu LGA of Delta state, Nigeria. These represent the prevalent types of buildings in Orhuwhorun, east of the oil rich city of Warri.

\section{Measurement Site C1 (Building with Concrete Slab Walls with embedded steel rod)}

Site C1 is a bungalow building located in Delta Steel Company Town 1 and Bbuilt in 1980. It consists of 4 sets of two bedroom flats surrounded by gardens and similar types of buildings, with the closest being $9.1 \mathrm{~m}$ away. A telecommunications tower is in the neighbourhood. $\mathrm{C} 1$ is $3.4 \mathrm{~m}$ high, $7.16 \mathrm{~m}$ wide and $33 \mathrm{~m}$ in long with external walls of $17.8 \mathrm{~cm}$ thick. The roof is asbestos, and the windows are casement glass with metal frame.

Measurements were made in the living room of the leftmost flat of site $\mathrm{C} 1$. Its size is $4.1 \mathrm{~m}$ by $4.11 \mathrm{~m}$. It has one iron door at the front, four wooden doors leading to various rooms in the apartment and one window with metal protector and screen. The size of each door is $2.1 \mathrm{~m}$ by $1 \mathrm{~m}$ and the window is $1.2 \mathrm{~m}$ by $1.8 \mathrm{~m}$. 


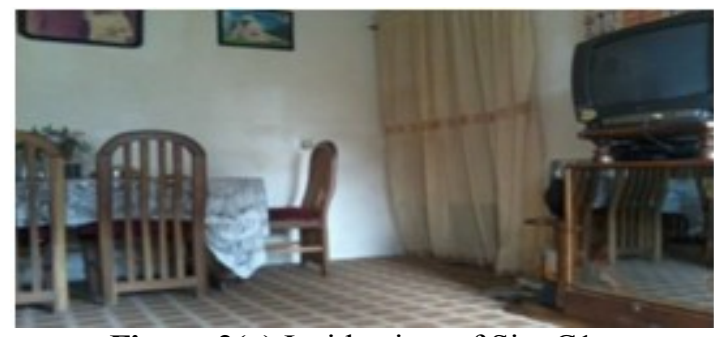

Figure 2(a) Inside view of Site C1

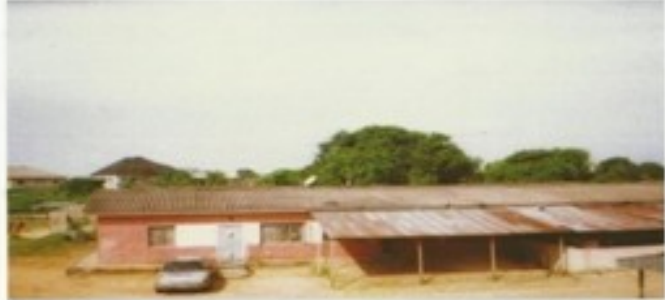

Figure 2(b) Outside view of Site C1

The floor is plastered with cement and covered with rug. Notable items within the site are upholstery chairs, a center table, a reading table with a set of chairs, musical set, a television receiver and a ceiling fan. The inside and outside views of site $\mathrm{C} 1$ are shown in Figure 2(a) and (b), respectively.

\section{Measurement Site B1 (building with block walls)}

Site B1 is in a building with block walls $17.8 \mathrm{~m}$, located in Orhuwhorun new Layout and built in 1994. It is enclosed within a perimeter block fence. Asbestos materials are used for both the roof and the ceiling. The closest distance of the building to the fence is $3.1 \mathrm{~m}$. There are similar types of building in the neighbourhood. The living room of site B1, where measurements were made is with an adjoining dining room. It is a $10.7 \mathrm{~m}$ by $4.5 \mathrm{~m}$ room, with terrazzo floor. The wooden doors with wooden frames which open into the living room are $1.9 \mathrm{~m}$ by $0.9 \mathrm{~m}$. The front door opens from outside into this room. All the windows are made of louvers with wooden frames and are $1.8 \mathrm{~m}$ by $1.1 \mathrm{~m}$ with burglary proof made from steel rods. Notable furniture items within the site are upholstery chairs, wooden center table and half upholstery-half wooden dining chairs and a wooden dining table. Musical set, television receiver, ceiling fans, refrigerator and deep freezer are among notable electrical appliances. The outside and inside views of site B1 are shown in Figure 3(a) and (b), respectively.

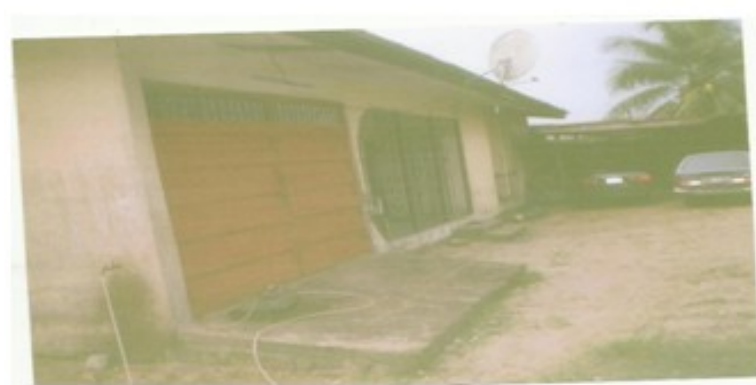

Figure 3(a) Outside view of Site C1

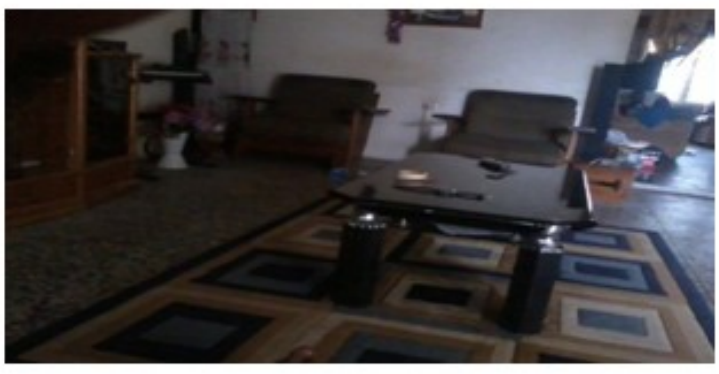

Figure 3(b) Inside view of Site C1

\section{Description of Measurement Tools}

The measurement tool was a Samsung Galaxy GT-35000 Mobile phone with RF Signal Tracker software installed in it. The measurement set-up is shown in figure 4[Omorogiwa and Edeko, 2009]. The RF Signal Tracker is a software that is compatible with some Samsung phones, with the capability of giving information on a BTS over the air interface, as well as information on the location of the mobile. The software comprises amongst others a scale capable of identifying the network provider, a scale capable of identifying the cell identity, a scale calibrated in decibel $(\mathrm{dBm})$, with which the received signal level of the MS is recorded. Others include a scale calibrated in distance terms $(\mathrm{Km})$, with which the distance of the location of the MS from the BTS is recorded, a scalecapable of giving the MS altitude and a scale capable of giving the GPS accuracy [RF Signal Tracker, retrieved $12^{\text {th }}$ November, 2012].

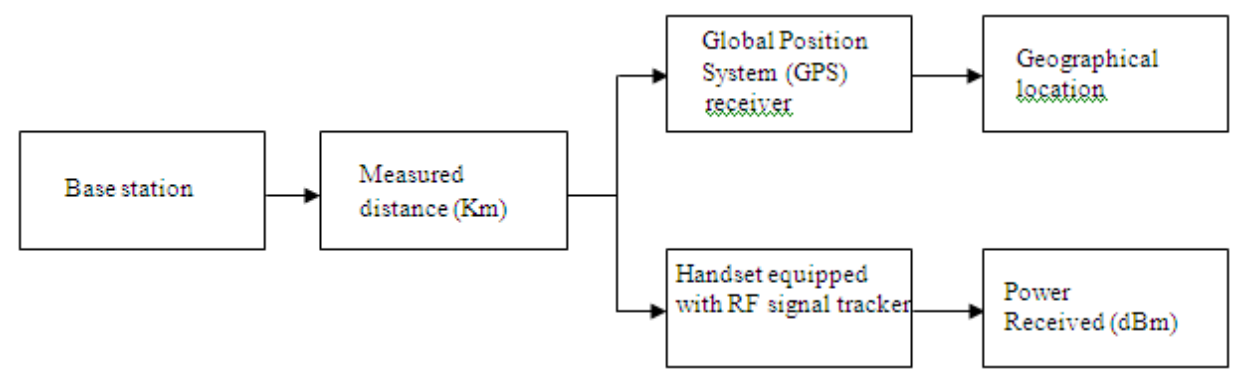




\section{Measurement Conditions}

Two existing GSM Operators, referred to as Operator A and Operator B, were used for the investigation. Measurements were made from January to June, 2013, a period of six months. Each site was visited everyday (between the hours of $11 \mathrm{am}$ and $3.30 \mathrm{pm}$ ) during this period and measurements were taken at ten evenly spaced predetermined points along the front wall of each site, inside and outside. The inside measurements were taken with all doors and windows closed since these structures affect RF signals. This represents the worst case indoor condition (which exists at night). The measurements were taken in the active mode.

Prior to the commencement of collection of data ten evenly spaced points were marked and labeled along the inside the front wall of each site and corresponding outside points were also marked.

\section{Description of Measurement Procedure}

RF Signal tracker was installed in each Samsung Mobile phones with SIM card of Operator and A Operator B, respectively. On each day and at each site a call was initiated from Operator A network to the corresponding MS and readings signal level indication at each marked point inside was recorded. Then the mobile was moved outside and readings were also recorded. This procedure was repeated with Operator A.

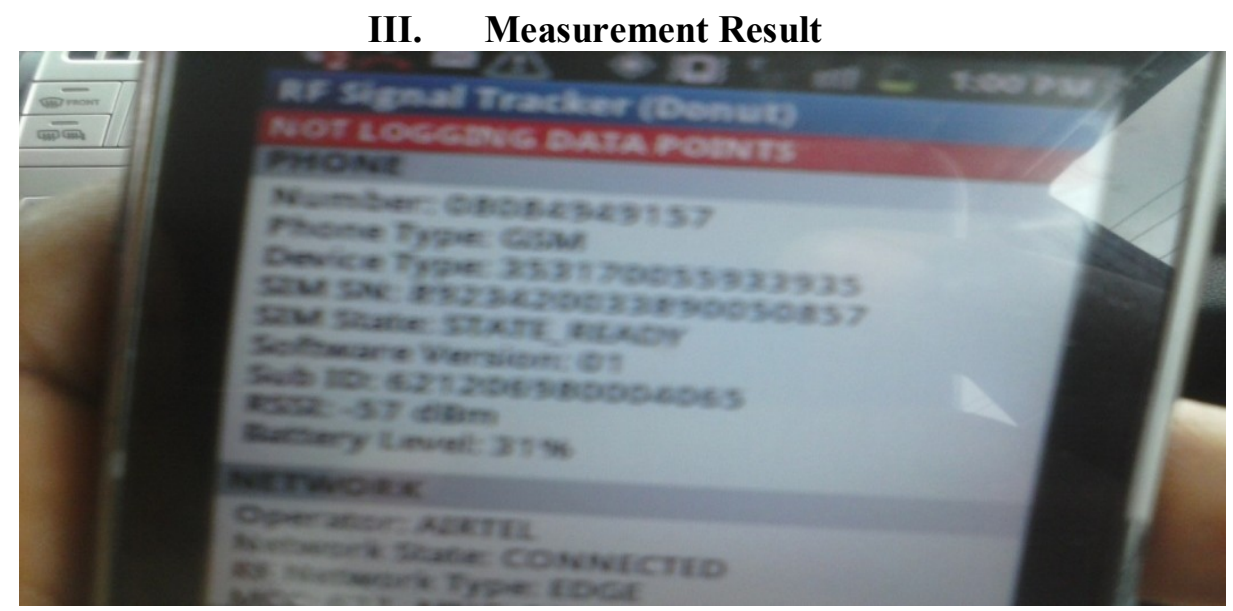

Figure 5 Samsung Galaxy MS with RF Signal Tracker software display for one outdoor measurement Figure 5 represents the actual constellation of received signal strength level outside one of the buildings recorded from the RF signal tracker. This is an example of a received signal strength level (RSSI) outside the concrete building from network A. The monthly average received signal level for each building are shown in table 1 and 2 . The average building penetration loss of the outer wall of the buildings that were investigated was computed using equation 1 . The result obtained is tabulated in table 1

Table 1 Monthly Measured Signal for Concrete C1

\begin{tabular}{|l|c|l|l|l|l|l|}
\hline \multirow{2}{*}{ Month } & \multicolumn{5}{|c|}{ Average Measured Monthly Signal (dBm) } \\
\cline { 2 - 7 } & \multicolumn{3}{|c|}{ Operator A at 472m } & \multicolumn{3}{c|}{ Operator B at 837m } \\
\cline { 2 - 7 } & Outside & Inside & BPL & Outside & Inside & BPL \\
\hline January & -59.46 & -68.50 & 9.04 & -73.93 & -83.71 & 9.78 \\
\hline February & -59.07 & -68.75 & 9.68 & -73.52 & -83.65 & 10.13 \\
\hline March & -58.63 & -68.92 & 10.29 & -73.93 & -84.37 & 10.44 \\
\hline April & -58.39 & -68.99 & 10.60 & -74.30 & -85.50 & 11.20 \\
\hline May & -58.15 & -68.97 & 10.82 & -72.92 & -84.96 & 12.04 \\
\hline June & -57.83 & -69.06 & 11.23 & -73.04 & -85.20 & 12.16 \\
\hline Mean Average & $\mathbf{- 5 8 . 5 9}$ & $\mathbf{- 6 8 . 8 7}$ & $\mathbf{1 0 . 2 8}$ & $\mathbf{- 7 3 . 6 1}$ & $\mathbf{- 8 4 . 5 7}$ & $\mathbf{1 0 . 9 6}$ \\
\hline
\end{tabular}

Table 2 Monthly Measured Signal for Block B1

\begin{tabular}{|c|c|c|c|c|c|c|}
\hline \multirow[b]{3}{*}{ Month } & \multicolumn{6}{|c|}{ Average Measured Monthly Signal (dBm) } \\
\hline & \multicolumn{3}{|c|}{ Operator A at $542 \mathrm{~m}$} & \multicolumn{3}{|c|}{ Operator B at $759 \mathrm{~m}$} \\
\hline & Outside & Inside & BPL & Outside & Inside & B PL \\
\hline January & -63.06 & -66.97 & 3.91 & -75.26 & -78.48 & 4.02 \\
\hline March & -62.71 & -66.72 & 4.01 & -73.64 & -78.15 & 4.41 \\
\hline April & -62.78 & -66.79 & 4.01 & -73.34 & -77.94 & 4.50 \\
\hline May & -63.18 & -67.24 & 4.06 & -73.95 & -78.57 & 4.62 \\
\hline Mean Average & -63.22 & -67.24 & 4.02 & -74.43 & -78.81 & 4.40 \\
\hline
\end{tabular}


Table 3 Average Building Penetration Loss of C1 and B1

\begin{tabular}{|c|c|c|c|}
\hline \multirow{2}{*}{ Building Type } & \multicolumn{2}{|c|}{ Average Penetration Loss (dBm) } & Mean Average Penetration Loss (dBm) \\
\cline { 2 - 3 } & Operator A & Operator B & \\
\hline C1 & 10.28 & 10.96 & 10.62 \\
\hline B1 & 4.02 & 4.40 & 4.21 \\
\hline
\end{tabular}

\section{Discussion Of Result}

The results obtained clearly show that the penetration loss of a building depends on the building wall type and that the loss of concrete with embedded steel rod is much higher than that of block type. This is probably because the concrete structure under investigation is more compact than the block building. Hence the more porous block building allows a better penetration of radio signals. A factor that may have contributed to the higher loss of the concrete wall is the fact that the embedded steel rods, being conductors tend to reflect incident electromagnetic wave, thereby reducing the forward energy that succeed in penetrating through the wall. Another factor which may have also contributed to this result is the fact that the louver window of the block building allows a better penetration of the waves than the casement type used in the concrete building.

The monthly values for the two buildings and the two GSM operators show that there are slight increases in the penetration loss progressively from January to June. This can be accounted for by the fact that penetration loss increases with increased humidity and that the volume of rainfall was greatest in the month of June amongst all others under consideration.

There were slight differences in Operator A and B values. This may be due to the fact that since the waves originated from different base stations at different locations they must have entered the buildings from different directions. And the direction of incident wave is known to affect penetration loss.

\section{Conclusion}

The result of this work shows that as a mobile unit is moved from outside to inside a building the path loss increases and that penetration loss of GSM signals is a function of the building wall type and that the loss through a concrete wall is higher than the loss through a block wall.

\section{References}

[1]. Adewoye, J. O and Obasa, K. A.(2010) Impact of Global System for Mobile Communication on Small Business Development, Journal of Management and Society 1(2) 44-50

[2]. Attah, O. W., (2013) In building penetration loss in office and residential building structures in Palestine at GSM 900 MHz frequency, Wireless Personal Communications 7(1)1-14.

[3]. Caluyo, F. S. and Dela Cruz, J. C. (2011), Penetration Loss of Doors and Windows inside Residences using ISDB-T Digital Terrestrial Television Signal at $677 \mathrm{MHz}$, Proceedings of the World Congress on Engineering and Computer Science, San Francisco, USA 2: 890-894.

[4]. Hasted, J. B. and Shah, M. A., (1964), Microwave absorption by water in building materials, British J. of Applied Physics 15:825 836.

[5]. Horikoshi, J; Tanaka, K. and T. Morinaga (1986) $1.2 \mathrm{GHz}$ band wave propagation measurements in concrete building for indoor radio communications, IEEE Trans. Vehicular. Technology, 35(4)146 - 152.

[6]. Omorogiwa, O., and Edeko, F. O. (2009) Investigation and Modelling of Power Received at 1800MHz in a Mountainous Terrain, International Journal of Electrical and Power Engineering, 129-135

[7]. Rappaport, T. S. (2003): Wireless Communications- Principles and Practice, $2^{\text {nd }}$ ed. Pearson Education PTE Ltd, Singapore, 105167 pp.

[8]. RF Signal Tracker, Android Apps on Google; Retrieved from https://play.google.com, Retrieved $12^{\text {th }}$ November, 2012.

[9]. Rice, L. P. (1959) Radio Transmission into buildings at 35 and $150 \mathrm{MHz}$, The Bell System Tech. Journal, 1(38)197-210.

[10]. Tanis, W. J. and Pilato G. J. (1993), Building penetration characteristics of $880 \mathrm{MHz}$ and 1922 MHz radio waves, IEEE Vehicular Technology 43: $206-209$

[11]. Turkmani, A. M. D. and De Toledo, A. F. (1991), Radio transmission at $1800 \mathrm{MHz}$ into and within, Multistory Buildings, IEE Proceedings Part I, 1(138) no 6, $577-584$.

[12]. Walker, E. H. (1983), Penetration of Radio Signals into Buildings in the Cellular Radio Environment, Bell System Technical Journal, 62(9) 2719-2734 